\title{
Do children report differently from their parents and from observed data? Cross-sectional data on fruit, water, sugar-sweetened beverages and break-time foods
}

\author{
V. M. van de Gaar', W. Jansen², M. J. J. van der Kleij ${ }^{3}$ and H. Raat ${ }^{1 *}$
}

\begin{abstract}
Background: Reliable assessment of children's dietary behaviour is needed for research purposes. The aim of this study was (1) to investigate the level of agreement between observed and child-reported break-time food items; and (2) to investigate the level of agreement between children's reports and those of their parents regarding children's overall consumption of fruit, water and sugar-sweetened beverages (SSB).

Methods: The children in this study were 9-13 years old, attending primary schools in Rotterdam, the Netherlands. Children were observed with respect to foods brought for break-time at school. At the same day, children completed a questionnaire in which they were asked to recall the food(s) they brought to school to consume during break-time. Only paired data (observed and child-reported) were included in the analyses ( $n=407$ pairs). To determine each child's daily consumption and average amounts of fruit, water and SSB consumed, children and their parents completed parallel questionnaires. Only paired data (parent-reported and child-reported) were included in the analyses $(n=275$ pairs). The main statistical measures were level of agreement between break-time foods, fruit, water and SSB; and Intra-class Correlation Coefficients (ICC).

Results: More children reported bringing sandwiches and snacks for break-time than was observed (73\% vs $51 \%$ observed and $84 \%$ vs $33 \%$ observed). The overall agreement between observed and child-reported break-time foods was poor to fair, with ICC range 0.16-0.39 $(p<0.05)$. Children reported higher average amounts of SSB consumed than did their parents ( 1.3 vs $0.9 \mathrm{~L} \mathrm{SSB}, p<0.001)$. Child and parent estimations of the child's water and fruit consumption were similar. ICC between parent and child reports was poor to good (range $0.22-0.62, p<0.05$ ).

Conclusion: Children report higher on amount of break-time foods as compared to observations and children's reports of SSB consumption are higher than those of their parents. Since the level of agreement between the observed breaktime foods and that reported by children and the agreement of child's intake between parent and child reports are relatively weak, future studies should focus on improving methods of evaluating children's consumption behaviour or on ways on how to best use and interpret multiple-source dietary intake data.
\end{abstract}

Trial registration: Current Controlled Trials NTR3400.

Keywords: Children, Parents, Observed behaviour, Sugar-sweetened beverages, Fruit, Water, Snacks, Break-time foods, Agreement

\footnotetext{
* Correspondence: h.raat@erasmusmc.nl

'Department of Public Health, Erasmus University Medical Centre, P.O. Box

20403000CA, Rotterdam, The Netherlands

Full list of author information is available at the end of the article
} 


\section{Background}

Insight into children's consumption habits is important for two main reasons. Firstly, it is widely known that eating and drinking habits can contribute to the development of childhood obesity [1]. Secondly, the consumption habits that we have as children continue into adulthood, when the risk of obesity remains [2]. Therefore, gaining insight into a child's consumption habit is important. However, for assessing dietary behaviour on the level of pre-specified foods and food groups there seems to be no perfect measurement method [3].

Interventions aimed at changing children's consumption behaviour are commonly evaluated using information on the habitual consumption behaviour of the child reported by parents $[4,5]$. Unfortunately, research has shown that parents may not always be a reliable source of information on the child's habitual intake of foods and drinks [6, 7]. In addition, social desirability, especially among parents, may lead to over-reporting of the intake of healthy food items and under-reporting of the intake of unhealthy food items [3].

The cognitive ability of children to self-report their intake of foods and food groups is also doubtful [8, 9]. The ability to self-report improves when a child grows older [5], with some suggesting that children should at least be $\geq 12$ years old to report more reliably on their dietary intake [10]. Other research has shown that children from the age of 8 years old may already be reliable sources of information regarding their own food intake over the past $24 \mathrm{~h}[5,8,11,12]$. However, due to their unfamiliarity with concepts such as 'frequency' and 'averaging, it is debatable whether children of this age respond accurately to food frequency questionnaires when items cover longer periods $[5,8,11]$. Indeed, when Börnhorst and colleagues investigated the nature and magnitude of selective misreporting of food intake of different food items, they found children's level of under-reporting to be $8.0 \%$, with over-reporting at $3.4 \%$ [3]. Other studies have shown under-reporting of intake to be significantly higher in obese children $[8,11,13]$. These same studies have also demonstrated that not only does the extent of misreporting increase with age, in contrast to previous mentioned studies [5, 10]. Also, those who under-report on one occasion are likely to under-report on a second occasion, in which case reporter bias cannot be eliminated by repeated measures. Then again, research by Burrows and colleagues suggests that children between the ages 8 and 11 years old may report reliably as compared to either their father or their mother with regard to the child's dietary intake of specific foods [14].

As can be concluded from the arguments above, all of the available methods for measuring dietary behaviour on the level of pre-specified foods and food groups may have some degree of misreporting and error [8, 11, 15-17], which makes measuring a child's habitual consumption a challenging aspect of behaviour research. As previous research has indicated, in order for us to choose the most accurate measurement method for assessing children's eating behaviour, we must improve our understanding of discrepancies between observed and reported behaviour [18-20].

The aim of this study was twofold: (1) to investigate the level of agreement between observed and childreported break-time food items; and (2) to investigate the level of agreement between children's reports and those of their parents regarding the children's overall consumption of fruit, water and sugar-sweetened beverages (SSB).

\section{Methods}

Our cross-sectional study used data from the populationbased 'Water campaign' intervention [21]. This controlled trial aims to assess the effects of a combined school- and community-based intervention on children's SSB consumption. The Medical and Ethical Review Committee of the Erasmus Medical Centre issued a 'declaration of no objection' (i.e. formal waver) for this study (reference number MEC-2011-183). Four primary schools located in multi-ethnic, socially deprived neighbourhoods in Rotterdam, the Netherlands, were included in the 'Water campaign' intervention study. This resulted in a total of 1288 children aged 6-13 years (grades 3-8) who were invited to participate. Passive parental consent was obtained. Parents (and children) received an information brochure to notify and inform them about the intervention and study participation. The study was also announced by the school, via the school letter and through the teachers and by flyers which were visible throughout the school. Parents (and children) were free to refuse participation without giving any explanation. They could do so by informing one of the teachers at their school or one of the researchers when present at school. At all times, the researchers could be contacted by a special phone-number or e-mail, for instance to decline participation [21].

The questionnaire items were based on previously widely used questionnaires, mainly used in earlier Dutch studies [22, 23]. We used two questionnaires to assess habitual consumption: one version was completed by children in grades 6-8 and another was completed by the parents of children in grades 3-8. Children filled in their questionnaire at school in the presence of a researcher and their teacher. The parent questionnaire was to be completed at home by the main caregiver of the child, within a period of maximum two months.

To objectively record what children brought to school to consume during break-time we used observation forms. These forms have been frequently applied for these kinds 
of information gathering by the Youth Health Care in recent years. Observations (unobtrusive) at school for children in grades 3-8 were conducted by trained public health professionals.

For the present study, we used baseline data from children in grades 6-8 only (aged 9-13 years). Pairing of data from the child questionnaires with data from the parent questionnaires or with data from the observations generated a study population of 539 children.

\section{Population characteristics}

Socio-demographic characteristics were obtained from parent and/or child reports: the parent and child questionnaires included items on child's gender, age, grade and ethnic background. Ethnic background was determined by country of birth of the parents according to definitions given by Statistics Netherlands [24]. The child's ethnic background was defined as Dutch only if both parents had been born in the Netherlands; if one of the parents had been born in another country, ethnic background was defined according to that country; and if both parents had been born in different foreign countries, ethnic background was defined as the mother's country of birth. Ethnic background was categorised as either Dutch, Surinamese/Antillean, Moroccan/Turkish or other/missing.

Gender, age and educational level of the caregiver were recorded. The caregiver's highest educational level was categorised as either 'high'; 'mid-high'; 'mid-low'; or 'low', based on standard Dutch cut-off points [25].

Trained personnel measured the child's height and weight at baseline. Weight status was determined by calculating Body Mass Index in $\mathrm{kg} / \mathrm{m}^{2}$ with height measured to the nearest $0.1 \mathrm{~cm}$ and weight measured to the nearest $0.2 \mathrm{~kg}$, in light clothing or gym clothes, according to a national standardized protocol for Youth Health Care [26]. Children were categorised as being either 'non-overweight' or 'overweight or obese', based on cut-off points published by the International Obesity Task Force [27].

\section{Data pairs from observations and child reports}

Trained public health professionals observed and registered which food items children brought along for the 10:00 am break at school. During the same morning, children completed a questionnaire in which they were asked to recall the food(s) they brought to school to consume during break-time. In Additional file 1: S1 and $\mathrm{S} 2$, the observation form and the child's questionnaire item are shown. Data from the observations and child reports were grouped into three categories ('sandwiches', 'fruit' and 'snacks') by two researchers independently of each other. Any inconsistencies were discussed and where necessary a third researcher was included in order to reach agreement. If food items did not fit into one of the categories, these items were coded as 'missing'
$(<5 \%)$. A 'nothing' category was added for those children who had brought nothing to eat during break-time. The four categories were dichotomised into (0) 'not brought along', and (1) 'yes, brought along'. Paired data (observed and child-reported) were included in the analyses $(n=407$ pairs).

\section{Data pairs from parent and child reports}

Children and their parents completed parallel questionnaires regarding the child's fruit, water and SSB intake. We assessed 'daily consumption' and 'average amounts consumed'. Data collection took place over a period of two months, in April and May. Paired data (parent-reported and child-reported) were included in the analyses ( $n=275$ pairs).

Daily consumption of fruit was measured using the question 'Does your child/do you consume fruit on a daily basis?', with answer categories 'no, not every day' or 'yes, every day'. Average amounts of fruit consumed was measured using the question 'On a day your child eats/you eat fruit, how many pieces of fruit does your child/do you consume on average?'. Answer possibilities ranged from 'half a piece of fruit' to 'two or more pieces of fruit'. Examples were given to assist respondents in determining the number of fruit pieces (e.g. tangerine as a half piece; an apple as one piece).

Daily consumption of water was assessed using the question 'Does your child/do you drink water on a daily basis?', with answer categories 'no, not every day' or 'yes, every day'. Average amounts of water consumed was measured using the question 'On a day your child drinks/you drink water, how many glasses of water does your child/do you consume on average?'. Answer possibilities ranged from 'none' to 'five or more glasses of water'. The total water intake per day, converted to litres (for comparison with SSB), was calculated by multiplying the number of glasses by an estimated average volume of $200 \mathrm{ml}$.

Daily consumption of SSB was measured using the question 'Does your child/do you drink SSB on a daily basis?', with answer categories 'no, not every day' or 'yes, every day'. Average amounts of SSB consumed was measured using the question 'On a day your child drinks/you drink SSB, how many glasses $(250 \mathrm{ml})$, cans $(330 \mathrm{ml})$ or bottles $(500 \mathrm{ml})$ does your child/do you consume on average a day?'. Answer categories ranged from 'none' to 'five or more'. The total SSB intake per day, converted to litres, was calculated by adding up the volumes of the total number of glasses, cans and bottles that were consumed. Examples of SSB were provided, based on our definition of SSB: Beverages containing added sugar, sweetened dairy products (e.g. chocolate milk), fruit juice (e.g. apple juice), soft drinks (e.g. cola) and energy drinks (e.g. sport energy 
drinks). In Additional file 1: S3, an overview of the questionnaire items used to assess SSB intake are given.

\section{Analysis}

For the dichotomous variables in the observed-child data pairs and parent-child data pairs, we calculated overall level of agreement (\% same quartile). Kappa was used as an effect-size measure for the level of agreement, ranging from '0' (agreement as expected by chance) to ' 1 ' (perfect agreement) [28]. Agreement strength was based on the following criteria: 0.00$0.20=$ 'poor'; $0.21-0.40=$ 'fair'; $0.41-0.60=$ 'moderate'; $0.61-0.80$ = 'good'; $0.81-1.00$ = 'very good' [29].

To explore the relationship between the different measurements methods with regard to consumption, Intraclass Correlation Coefficients (ICC) were calculated for each of the analysed behaviours. This generated a measure of absolute agreement for the dichotomous variables.
For the continuous variables in the parent-child data pairs, the calculated ICC was a measure of consistency. The ICC is a value that ranges between ' 0 ' and ' 1 ', with a higher ICC corresponding to a better correlation. The following ICC cut-points were used: $0.00-0.20=$ 'poor'; $0.21-0.40=$ 'fair'; $\quad 0.41-0.60=$ 'moderate'; $\quad 0.61-0.80$ = 'good'; $0.81-1.00$ = 'very good' $[30,31]$. The mean (SD) of the difference and the limits of agreement were also calculated using Paired T-tests and used for input for the Bland Altman plots [32].

The McNemar test was used to compare the child's reports with that of the observed reports or the reports by parents (level of significance set at $5 \%$ ) [32].

\section{Results}

Table 1 provides information about several population characteristics. In the observed-child data pairs $(n=407)$, the children's mean age was 10.6 years (SD 1.1), $49.5 \%$

Table 1 Characteristics of children and caregivers included in study

\begin{tabular}{|c|c|c|c|c|}
\hline \multirow[b]{2}{*}{ Child characteristics } & \multicolumn{2}{|c|}{ Observed-child data pairs $n=407$} & \multicolumn{2}{|c|}{ Parent-child data pairs $n=275$} \\
\hline & $n$ & Mean (SD) or \% & $n$ & Mean (SD) or \% \\
\hline Gender, \% girls & 200 & $49.5 \%$ & 150 & $54.5 \%$ \\
\hline missing & 3 & $0.7 \%$ & 0 & $0.0 \%$ \\
\hline Age & 406 & $10.64(1.1)$ & 274 & $11.06(1.0)$ \\
\hline missing & 1 & $0.2 \%$ & 1 & $0.4 \%$ \\
\hline \multicolumn{5}{|l|}{ Grade } \\
\hline - Grade 6 & 161 & $39.6 \%$ & 97 & $35.3 \%$ \\
\hline - Grade 7 & 78 & $19.2 \%$ & 101 & $36.7 \%$ \\
\hline - Grade 8 & 168 & $41.2 \%$ & 77 & $28.0 \%$ \\
\hline missing & 0 & $0.0 \%$ & 0 & $0.0 \%$ \\
\hline \multicolumn{5}{|l|}{ Ethnicity } \\
\hline - Dutch & 93 & $22.9 \%$ & 56 & $20.4 \%$ \\
\hline - Surinamese/Antillean & 97 & $23.8 \%$ & 56 & $20.4 \%$ \\
\hline - Moroccan/Turkish & 118 & $29.0 \%$ & 90 & $32.7 \%$ \\
\hline - Other/missing & 99 & $24.3 \%$ & 73 & $26.5 \%$ \\
\hline Weight status, \% overweight/obese & 89 & $22.6 \%$ & 68 & $25.9 \%$ \\
\hline missing & 13 & $3.2 \%$ & 12 & $4.4 \%$ \\
\hline \multicolumn{5}{|l|}{ Caregiver characteristics } \\
\hline Age & - & - & 273 & $38.42(9.1)$ \\
\hline missing & & & 2 & $0.7 \%$ \\
\hline Gender, \% female & - & - & 223 & $88.8 \%$ \\
\hline missing & & & 24 & $8.7 \%$ \\
\hline Level of Education & - & - & & \\
\hline - High & & & 45 & $16.7 \%$ \\
\hline - Mid-high & & & 77 & $28.6 \%$ \\
\hline - Mid-low & & & 74 & $27.5 \%$ \\
\hline - Low & & & 73 & $27.1 \%$ \\
\hline missing & & & 6 & $2.2 \%$ \\
\hline
\end{tabular}


were girls, $22.9 \%$ were of Dutch origin, and $22.6 \%$ were overweight or obese.

In the parent-child data pairs $(n=275)$, the children's mean age was 11.1 years (SD 1.0), $54.5 \%$ were girls, $20.2 \%$ were of Dutch origin, and $26.0 \%$ were overweight or obese. With regard to the caregivers, $88.8 \%$ were female, their mean age was 38.4 years (SD 9.1), and $27.1 \%$ were classified as having a low level of education.

\section{Observed-child data pairs}

Table 2 shows the results of the analyses of the observed and child reports. Relative to observed reports of brought foods, the children themselves reported a higher amount of sandwiches (73.0\% vs $50.6 \%$ observed) and snacks ( $83.8 \%$ vs $33.2 \%$ observed).

The level of agreement was poor (total $\mathrm{\kappa}$ range $0.11-0.24$, $p<0.05)$. The ICC between the observed and childreported brought break-time foods was poor to fair (total ICC range $0.16-0.39, p<0.05)$.

\section{Parent-child data pairs}

Table 3 shows the mean and (SD) of average amounts of fruit, water and SSB consumed and the proportion who consume these items daily as reported by parents and children. In Additional file 1: S4, the Bland Altman plots are given.

Average amounts of fruit consumed reported by parents and children was similar in both groups and children reported a slightly lower daily consumption of fruit compared to their parents report. The level of agreement was poor ( $\mathrm{k}$ daily fruit $=0.12, p=0.047$ ), with overall agreement between children and parents of $56.8 \%$.

The average amounts of water consumed in litres reported by parents and children was similar. Children reported consuming water on a daily basis significantly more often as compared to their parents report. The level of agreement was moderate ( $\mathrm{k}$ daily water $=0.44, p<0.001$ ).

The average amounts of SSB consumed in litres reported by children was significantly higher than the volume reported by their parents. Children indicated consuming SSB on a daily basis also significantly less frequent than did their parents. Level of agreement was poor ( $\mathrm{\kappa}$ daily SSB $=0.19, p=0.001$ ).

The ICCs between the child and parent reports were poor to good (total ICC range 0.22-0.62). For fruit consumption, the ICC ranged from 0.22 to 0.39 (fair ICC, $p<0.05$ ) and for SSB consumption from 0.32 to 0.44 (fair to moderate ICC, $p<0.001$ ); the ICC for water consumption was the highest, with a range of $0.59-0.62$ (moderate to good ICC, $p<0.001$ ).

The results are reported in accordance with STROBE (Strengthening the Reporting of Observational Studies in Epidemiology). See Additional file 2 for the STROBE checklist [33].

\section{Discussion}

The level of agreement between the observed break-time foods and the children's self-report was poor to fair: children reported higher quantities on their break-time foods of sandwiches and snacks. There was a poor level of agreement between the reports from parents and children regarding whether children consumed fruit and SSB daily, and a moderate level of agreement for daily water consumption. Despite these differences, on a group level children and parents did report similar average amounts regarding what the child consumes on a day and whether or not he/she drinks water or eats fruit, with the highest ICC for water (good agreement). The reports on average amounts of SSB consumed differed substantially between children and parents however.

Our result of $67 \%$ overall agreement between observed and child-reported break-time foods is similar to that seen in previous studies. For example, in a study by Weber and colleagues, children were able to correctly recall $75 \%$ of the school meal foods that observers had documented that they had on their plate [34]. Subsequently, Baranowski and colleagues found $83 \%$ agreement between observed and recalled 12-h food consumption among children [35]. Despite this agreement, we also found differences, for example between observed and child-reported sandwich intake. The higher reported amounts by children could be explained

Table 2 Agreement between observed and child reports on food items that children brought to school with the intention to consume during break-time at school

\begin{tabular}{|c|c|c|c|c|c|c|c|}
\hline Primary outcomes - categories & $N$ & $\begin{array}{l}\text { Number of times } \\
\text { observed }(\%)^{5}\end{array}$ & $\begin{array}{l}\text { Number of times reported } \\
\text { by child }(\%)^{5}\end{array}$ & Overall agreement & Kappa $^{1,2}$ & $P$-value ${ }^{3}$ & $\mathrm{ICC}^{1,4}$ \\
\hline 'Nothing' (brought nothing with them) & 407 & $16(3.9 \%)$ & $7(1.7 \%)$ & $95.8 \%$ & $.24 * * *$ & 0.049 & $.39 * * *$ \\
\hline Sandwiches & 407 & $206(50.6 \%)$ & 297 (73.0 \%) & $54.6 \%$ & .09 & $<0.001$ & $.16 *$ \\
\hline Fruit \& vegetables & 407 & $76(18.7 \%)$ & $39(9.6 \%)$ & $78.1 \%$ & $.11 *$ & $<0.001$ & $.21 * *$ \\
\hline Snacks & 407 & 135 (33.2 \%) & 341 (83.8 \%) & $38.1 \%$ & .01 & $<0.001$ & .02 \\
\hline
\end{tabular}

${ }^{1}$ Significance (2-tailed): ${ }^{*} 0.05$ level, ${ }^{* *} 0.01$ level, ${ }^{* * *} \leq 0.001$ level

${ }^{2}$ Cohen's Kappa - corrected for agreement based on chance

${ }^{3}$ McNemar test

${ }^{4}$ Average Intra-class Correlation Coefficients (ICC) resembles measure of absolute agreement

${ }^{5}$ In case multiple food items were brought for break-time, the sum of the category percentages may exceed $100 \%$ 
Table 3 Agreement between parent and child reports on consumption of fruit, water and sugar-sweetened beverages (SSB)

\begin{tabular}{|c|c|c|c|c|c|c|c|c|}
\hline Primary outcomes & $N$ & $\begin{array}{l}\text { Parent reported } \\
\text { Mean (SD) or } \mathrm{n}(\%)\end{array}$ & $\begin{array}{l}\text { Child reported } \\
\text { Mean (SD) or n (\%) }\end{array}$ & $\begin{array}{l}\text { Difference } \\
\text { Mean (SD) } \\
\end{array}$ & Overall agreement & Kappa ${ }^{1,2}$ & $P$-value ${ }^{3}$ & $\mathrm{ICC}^{1,4}$ \\
\hline $\begin{array}{l}\text { Average amount of fruit } \\
\text { consumed (\# pieces) }\end{array}$ & 252 & $1.42(0.5)$ & $1.48(0.5)$ & $0.06(0.6)$ & - & - & 0.150 & $.39 * * *$ \\
\hline Daily fruit $\%$ yes & 250 & $117(46.8 \%)$ & 99 (39.6 \%) & - & $56.8 \%$ & $.12 *$ & 0.101 & $.22 *$ \\
\hline $\begin{array}{l}\text { Average amount of water } \\
\text { consumed }(L)\end{array}$ & 253 & $0.63(0.3)$ & $0.66(0.3)$ & $0.04(0.3)$ & - & - & 0.065 & $.59 * * *$ \\
\hline Daily water $\%$ yes & 258 & $174(67.4 \%)$ & $194(75.2 \%)$ & - & $76.7 \%$ & $.44^{* * *}$ & 0.013 & $.61 * * *$ \\
\hline $\begin{array}{l}\text { Average amount of SSB } \\
\text { consumed }(\mathrm{L})\end{array}$ & 253 & $0.92(0.6)$ & $1.33(0.8)$ & $0.41(0.9)^{* * *}$ & - & - & $<0.001$ & $.44^{* * *}$ \\
\hline Daily SSB \% yes & 258 & $141(54.7 \%)$ & 83 (32.2 \%) & - & $58.1 \%$ & $.19^{* *}$ & $<0.001$ & $.32 * * *$ \\
\hline
\end{tabular}

${ }^{1}$ Significance (2-tailed): ${ }^{*} 0.05$ level, ${ }^{* *} 0.01$ level, ${ }^{* * *} \leq 0.001$ level

${ }^{2}$ Cohen's Kappa - corrected for agreement based on chance

${ }^{3}$ McNemar test (dichotomous variables) or Paired $T$-test (continues variables)

${ }^{4}$ Average Intra-class Correlation Coefficients (ICC) resembles measure of absolute agreement (dichotomous variables) or consistency (continues variables)

by the fact that while observers only counted the sandwiches that children brought to school to eat during break-time at 10:00 am, some children may well have reported the number of sandwiches brought to consume during both break-time and lunch. Apart from this, our overall findings indicate that children also report higher amounts of their break-time snacks. A further possible explanation for this lack of agreement is that children find it difficult to estimate the amount of foods and food items, as other studies have reported $[8,9,11]$.

Whereas on a group level the reports from parents and children regarding average amounts of fruit and water consumed were similar, those regarding average amounts of SSB consumed were dissimilar. These discrepancies could be due to children being more aware of when and how much fruit and water they consume than how much SSB they consume $[8,9,11]$. Fruit and water may be more straightforward than SSB. Although the definition of SSB was explained to the children and examples of SSB were provided, the children may still not have completely understood what SSB is. After all, it is more difficult to recall your consumption behaviour if you do not fully understand what it is you were supposed to remember, for example when remembering which drinks to include when answering certain questions. As a further explanation for such misreporting, one could consider the argument that healthier food or drink types such as fruit and water are more likely to be over-reported than unhealthy food or drink types such as SSB. This has been addressed by Börnhorst and colleagues in the context of intentional selective misreporting by parents (of 6101 children aged 2-9; mean age 6.1 (SD 1.8)): this study found that foods perceived as unhealthy (such as sugary products) were more likely to be under-reported whereas foods perceived to be more healthy (such as fruit and vegetables) were less likely to be under-reported [3]. So it would seem that there is a tendency towards over-reporting of healthier habits and towards socially desirable answers by parents [36, 37]. This might explain why, in the current study, average amounts of SSB consumed was dissimilar between parent and child reports while average amounts of fruit and water consumed was not. Yet another possible explanation for the discrepancy between child and parent report could be that children could have bought or swapped food items, without their parents knowing. In particular, this could especially be the case for items such as SSB's. However, the potential over-reporting of healthy foods by parents could mean in our case that water and fruit intake reports of parents are higher than the true intake. Yet, children and parents reports on the child's intake of fruit and water were similar. The role of social desirability on the answers of parents or children therefore stays obscure. Therefore, further research is required to address whether there are indeed differences between parents' and children's reports of healthy and unhealthy consumption in children.

The time between the child and parent reports ranged from one day to two months. Theoretically it is possible that seasonal influences on eating patterns or changes in feeding behaviours could have contributed to the discrepancies between self-reports of parents and children. Because our questions were on daily consumption and average amounts consumed, we assume that if this time delay between reports of parents and children was of influence, it will be of small influence since habit strength in consumption and feeding patterns tends to be high [38].

Others have looked for explanations for the discrepancies seen between parents and children. For example, McPherson and colleagues [8] suggest that one of the reasons that parents and children report different intakes is that they have different perceptions of the child's food and drink intake. Additionally or alternatively, the discrepancy between parents and children could be explained by reporting bias, with parents reporting socially desirable answers more frequently than children [3]. 
A possible explanation for the higher reports of snacks as break-time food item (and possible over-reporting of SSB) by children could be due to personal preferences or personal characteristics, for example. Since snacks (and SSB) are more likely to be children's favourite food (or drink) types, this could have been reflected in their reporting behaviour. In addition, we found statistically significant differences between the children's reports of obesity-related foods and beverages and that observed or reported by parents, however hereby we contradict the findings found by Bennett and colleagues [36].

Previous research among parents and children reporting on child's consumption behaviour has found that parental reports are slightly more accurate than children's reports: $78 \%$ compared with $72 \%$ agreement regarding different food items and food types (children under study between the ages of 6 ang 11 years old) [15]. Given the differences and low levels of agreement that we found, we would recommend combined measurement methods when assessing child's habitual dietary behaviour on the level of pre-specified foods or food groups. This is also suggested by Eck and colleagues who concluded in their study that the children's contribution could be of value, given that the combined parent-and-child report was more accurate that the individual parent report (children under study between the ages of 4 and 10 years old) [7]. Reports from multiple sources are therefore recommended over single-source reports, especially for children younger than the age of 8 years old as proposed by Burrows and colleagues [4]. As seen in other public health fields, the question then remains on how to process data from multiple sources [39].

\section{Strengths and limitations}

One of the strengths of this study is that it provides a unique assessment of different types of behaviour consumption in an ethnically diverse population. A further strength is the combined use of three measures - observations, parent questionnaires and child questionnaires - which provides insight into the added value of the various different assessment methods.

However, there are also limitations which should be acknowledged. Firstly, a maximum period of up to two months could have elapsed between completion of the child questionnaire and the parent questionnaire. Although our questions considered daily consumption and average amounts consumed, the time delay between parent and child reports has to be acknowledged when interpreting the results. Also, the data collection took place in the months April and May. As mentioned before, a seasonal effect cannot be ruled out, but given the timing of the measurements, we assume this is unlikely. Secondly, the questionnaire was provided in Dutch only, which could have been a barrier for some parents given the diverse ethnicity of our study population. Although we provided parents and children with definitions and examples, there may have been some confusion as to what constitutes the different snack and SSB categories. For instance, some members of the general population may not be aware of the differences between fruit juices such as apple juice and sweetened dairy products or energy drinks. Also, mis-categorisation by observers and children could have occurred when reporting on the brought food items. Lastly, regarding the parent-child comparison, we do not have an objective measurement of the reported intake and therefore cannot say anything about the 'true' intake, which is a limitation of the utility of that data.

\section{Conclusion}

Children not only report higher than observed on amount of break-time foods of sandwiches and snacks, they also report a higher SSB intake than that reported by their parents. However, children and parents have similar estimations of the child's water and fruit consumption. Since the level of agreement between the observed break-time foods and that reported by children and the agreement of child's intake between parent and child reports are relatively weak, future studies should focus on improving methods of evaluating children's consumption behaviour or on ways on how to best use and interpret multiple-source dietary intake data.

\section{Additional files}

Additional file 1: S1. Observation form. S2. Questionnaire item child. S3. Table: Overview of items used to assess child's SSB intake in the parent and child questionnaire. S4. Bland Altman plots. 3a. Bland Altman plot - Water (L). 3b. Bland Altman plot - Fruit (\# pieces). 3c. Bland Altman plot - Sugar-sweetened beverages (L) (PDF $731 \mathrm{~kb}$ )

Additional file 2: STROBE checklist. (DOCX 29 kb)

Abbreviations

ICC: intra-class correlation coefficients; SSB: sugar-sweetened beverages.

Competing interests

The authors declare that they have no competing interests.

Authors' contributions

VvdG and WJ conceived the idea. VvdG was primarily responsible for drafting the manuscript and Tables. $V v d G$ is responsible for the data collection, data analysis and reporting the study results. HR and WJ supervised the study and helped to refine the manuscript. MvdK contributed to the draft of the manuscript and helped to refine the manuscript. All authors regularly participated in discussing the design and protocols used in the study. All authors read and approved the final manuscript.

\section{Acknowledgments}

This study is funded by a grant from the major funding body ZonMw, the Netherlands Organization for Health Research and Development, project no. 200100001 (50-50102-96-015). This study is part of the Dutch project CIAO, which stands for Consortium Integrated Approach Overweight. Within CIAO, several studies are conducted investigating the different components of the 
EPODE approach. The publication of this study was supported by a grant of the Netherlands Organization for Scientific Research (NWO).

\section{Author details}

1 Department of Public Health, Erasmus University Medical Centre, P.O. Box 20403000CA, Rotterdam, The Netherlands. ${ }^{2}$ Department of Social Development, City of Rotterdam, P.O. Box 10243000BA, Rotterdam, The Netherlands. ${ }^{3}$ Department of Public Health \& Primary Care, Leiden University Medical Centre, P.O. Box 96002300RC, Leiden, The Netherlands.

\section{Received: 25 November 2015 Accepted: 15 March 2016} Published online: 18 April 2016

\section{References}

1. Swinburn BA, Caterson I, Seidell JC, James WP. Diet, nutrition and the prevention of excess weight gain and obesity. Public Health Nutr. 2004; 7(1A):123-46.

2. Mikkila V, Rasanen L, Raitakari OT, Pietinen P, Viikari J. Consistent dietary patterns identified from childhood to adulthood: the cardiovascular risk in Young Finns Study. Br J Nutr. 2005:93(6):923-31.

3. Bornhorst C, Huybrechts I, Ahrens W, Eiben G, Michels N, Pala V, Molnar D, Russo P, Barba G, Bel-Serrat S, et al. Prevalence and determinants of misreporting among European children in proxy-reported 24 h dietary recalls. Br J Nutr. 2013;109(7):1257-65.

4. Burrows TL, Martin RJ, Collins CE. A systematic review of the validity of dietary assessment methods in children when compared with the method of doubly labeled water. J Am Diet Assoc. 2010;110(10):1501-10.

5. Livingstone MB, Robson PJ, Wallace JM. Issues in dietary intake assessment of children and adolescents. Br J Nutr. 2004;92 Suppl 2:S213-22.

6. Baranowski T, Sprague D, Baranowski JH, Harrison JA. Accuracy of maternal dietary recall for preschool children. J Am Diet Assoc. 1991:91(6):669-74.

7. Eck LH, Klesges RC, Hanson CL. Recall of a child's intake from one meal: are parents accurate? J Am Diet Assoc. 1989:89(6):784-9.

8. McPherson RS, Hoelscher DM, Alexander M, Scanlon KS, Serdula MK. Dietary assessment methods among school-aged children: Validity and reliability. Prev Med. 2000;31(2):S11-33

9. Smith AF, Baxter SD, Hardin JW, Guinn $\mathrm{CH}$, Royer JA. Relation of Children's Dietary reporting accuracy to cognitive ability. Am Epidemiol. 2011;173(1):103-9.

10. Field AE, Peterson KE, Gortmaker SL, Cheung L, Rockett H, Fox MK, Colditz GA Reproducibility and validity of a food frequency questionnaire among fourth to seventh grade inner-city school children: implications of age and day-to-day variation in dietary intake. Public Health Nutr. 1999;2(3):293-300.

11. Livingstone MB, Robson PJ. Measurement of dietary intake in children. Proc Nutr Soc. 2000;59(2):279-93.

12. Hunsberger M, Pena P, Lissner L, Grafstrom L, Vanaelst B, Bornhorst C, Pala V , Eiben $\mathrm{G}$. Validity of self-reported lunch recalls in Swedish school children aged 6-8 years. Nutr J. 2013:12(1):129.

13. Waling MU, Larsson CL. Energy intake of Swedish overweight and obese children is underestimated using a diet history interview. J Nutr. 2009;139(3):522-7

14. Burrows TL, Truby H, Morgan PJ, Callister R, Davies PS, Collins CE. A comparison and validation of child versus parent reporting of children's energy intake using food frequency questionnaires versus food records: who's an accurate reporter? Clin Nutr. 2013;32(4):613-8.

15. Mack KA, Blair J, Presser S. Measuring and improving data quality in children's reports of dietary intake. In: Colorado RWB, editor. Conference on health survey research methods. 1995.

16. Cade JE, Burley VJ, Warm DL, Thompson RL, Margetts BM. Food-frequency questionnaires: a review of their design, validation and utilisation. Nutr Res Rev. 2004:17(1):5-22.

17. Dwyer JT, Krall EA, Coleman KA. The problem of memory in nutritional epidemiology research. J Am Diet Assoc. 1987;87(11):1509-12.

18. Pinard CA, Davy BM, Estabrooks PA. Beverage intake in low-income parentchild dyads. Eat Behav. 2011:12(4):313-6.

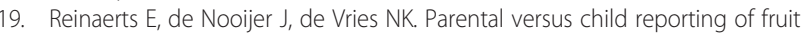
and vegetable consumption. Int J Behav Nutr Phys Act. 2007:4:33.

20. Tak NI, te Velde SJ, de Vries JH, Brug J. Parent and child reports of fruit and vegetable intakes and related family environmental factors show low levels of agreement. J Hum Nutr Diet. 2006;19(4):275-85.
21. van de Gaar VM, Jansen W, van Grieken A, Borsboom G, Kremers S, Raat H. Effects of an intervention aimed at reducing the intake of sugar-sweetened beverages in primary school children: a controlled trial. Int J Behav Nutr Phys Act. 2014;11:98.

22. van der Horst $K$, Oenema A, van de Looij-Jansen P, Brug J. The ENDORSE study: research into environmental determinants of obesity related behaviors in Rotterdam schoolchildren. BMC Public Health. 2008;8:142.

23. Veldhuis L, Struijk MK, Kroeze W, Oenema A, Renders CM, Bulk-Bunschoten AM, Hirasing RA, Raat H. 'Be active, eat right', evaluation of an overweight prevention protocol among 5-year-old children: design of a cluster randomised controlled trial. BMC Public Health. 2009:9:177.

24. Swertz O, Duimelaar $P$, Thijssen J. Statistics netherlands. migrants in the netherlands 2004. Voorburg/Heerlen: Statistics Netherlands; 2004

25. Netherlands S. Dutch standard classification of education 2003. Voorburg/ Heerlen: Statistics Netherlands; 2004.

26. Bulk-Bunschoten AMW, Renders CM, Leerdam FJM, Hirasing RA. Protocol for detection of overweight in preventive youth health care. [Signaleringsprotocol overgewicht in de jeugdgezondheidszorg]. Amsterdam: VUMC; 2004

27. Cole TJ, Bellizzi MC, Flegal KM, Dietz WH. Establishing a standard definition for child overweight and obesity worldwide: international survey. BMJ. 2000; 320(7244):1240-3.

28. Bland JM, Altman DG. Statistical methods for assessing agreement between two methods of clinical measurement. Lancet. 1986:1(8476):307-10.

29. Altman D. Practical statistics for medical research. London: Chapman and Hall; 1990

30. de Vet HC, Terwee CB, Knol DL, Bouter LM. When to use agreement versus reliability measures. J Clin Epidemiol. 2006;59(10):1033-9.

31. Costa-Santos C, Bernardes J, Ayres-de-Campos D, Costa A, AmorimCosta C. The limits of agreement and the intraclass correlation coefficient may be inconsistent in the interpretation of agreement. Clin Epidemiol. 2011;64(3):264-9.

32. Field A. Discovering statistics using SPSS. 2nd ed. London: SAGE Publications; 2005

33. von Elm E, Altman DG, Egger M, Pocock SJ, Gøtzsche PC, Vandenbroucke JP; STROBE Initiative. The Strengthening the Reporting of Observational Studies in Epidemiology (STROBE) statement: guidelines for reporting observational studies. Lancet. 2007 Oct 20;370(9596):1453-7. PMID: 18064739.

34. Weber JL, Lytle L, Gittelsohn J, Cunningham-Sabo L, Heller K, Anliker JA, Stevens J, Hurley J, Ring K. Validity of self-reported dietary intake at school meals by American Indian children: the Pathways Study. J Am Diet Assoc. 2004;104(5):746-52.

35. Baranowski T, Dworkin R, Henske JC, Clearman DR, Dunn JK, Nader PR, Hooks PC. The accuracy of children's self-reports of diet: Family Health Project. J Am Diet Assoc. 1986:86(10):1381-5.

36. Bennett CA, de Silva-Sanigorski AM, Nichols M, Bell AC, Swinburn BA. Assessing the intake of obesity-related foods and beverages in young children: comparison of a simple population survey with $24 \mathrm{hr}$-recall. Int J Behav Nutr Phys Act. 2009:6:71

37. Martins CC, Oliveira MJ, Pordeus IA, Paiva SM. Comparison between observed children's tooth brushing habits and those reported by mothers. BMC Oral Health. 2011:11:22

38. McGowan L, Cooke LJ, Gardner B, Beeken RJ, Croker H, Wardle J. Healthy feeding habits: efficacy results from a cluster-randomized, controlled exploratory trial of a novel, habit-based intervention with parents. Am J Clin Nutr. 2013:98(3):769-77.

39. Kraemer HC, Measelle JR, Ablow JC, Essex MJ, Boyce WT, Kupfer DJ. A new approach to integrating data from multiple informants in psychiatric assessment and research: mixing and matching contexts and perspectives. Am J Psychiatry. 2003;160(9):1566-77. 